\title{
Knowledge Management Environment for Collaborative Design in Product Development
}

\author{
Shuai Zhang \\ University of Greenwich, Greenwich SE10 9LS London, UK \\ Shuai.Zhangegreenwich.ac.uk
}

\begin{abstract}
.
Knowledge management environments are being developed for product development activities to help companies reuse their knowledge. This trend has been identified in manufacturing companies, which operate product design departments at various locations. Investigating how these companies can configure their knowledge management environments to fulfil engineers' knowledge needs in deign activities opens up a research topic for us. A well configured knowledge management environment (KME) will require a clear understanding of what relevant roles need from it. The research focuses on the structures and operations of knowledge sharing for product development. A case study of four manufacturing companies was conducted to understand their KMEs.

The study reported in this report contributes to theory by providing an understanding of the structure of KMEs in companies. Researchers in the domain of knowledge management can develop a good understanding of how engineers interact with KMEs so that researchers can propose knowledge management systems or methods that make tangible improvements. This study also helps engineers map out the KMEs that they search to fulfil their knowledge queries. Chief engineers or managers in companies who are in charge of knowledge management can benefit from the understanding of their own KMEs. The study also suggests future research directions, such as identifying and proposing the indicators that can be used to measure the performance of knowledge re-use.
\end{abstract}

Keywords: Knowledge Management, Interorganisational System, Engineering Design.

\section{Introduction}

Knowledge management can help companies reuse the knowledge generated when designing previous products. Researchers in this domain have proposed and investigated knowledge systems for the capture, storage and retrieval $[1,2,3]$. Studies also addressed some of the knowledge queries that engineers make in design and how they interact with specific knowledge management systems [4, 5]. Although some studies have attempted to investigate information needs, knowledge sources and interorganisational systems for engineering design $[6,7]$, there is a lack of systematic 
knowledge for understanding the KMEs that companies provide for engineers. Thus, the proposed research question for this report is 'What are the structures and configurations of KMEs to support engineers in collaborative design?' By answering this question, the research will build up new knowledge about knowledge management for engineering design, which can help companies manage their knowledge reuse.

The report presents case studies of KMTs for four manufacturing companies. It starts with discussing the three terms of data, information and knowledge, followed by reviewed literature on knowledge management in engineering design. Section 3 explains how the research is designed and how data is collected and analysed. Section 4 and 5 presents the findings of case study and discussion, including the features of KMTs.

\section{$2 \quad$ Literature Review}

Literature in knowledge management usually distinguishes between data, information and knowledge, or at least defines the term 'knowledge' explicitly. There is a consensus among many researchers that the relationship between data, information and knowledge. The general view is that a large amount of data is refined and combined into meaningful structures to create smaller amounts of information, followed by further distillation when meaningful information is put into context to create knowledge. Ackoff [8] believes that data are symbols representing the properties of objects and events, while information is useful processed data. Information is contained in descriptions and provides answers to the questions of who, what, when, where, and how many. Knowledge is conveyed by instructions and provides the answers to 'howto' questions. This report focuses on data, information and knowledge as the three terms which cover all entities involved in knowledge management in current engineering design context.

The general view that knowledge is something more than information has resulted in distinctions being drawn between data, information and knowledge by many authors. Spek and Spijkervet [9] believe that data are understood as uninterpreted symbols, information is data endowed with meanings, and knowledge is understanding that is used to assign meanings to information. Davenport [10] says that data are segmented observations, information is data processed with relevance and purpose, and knowledge is information with value. Sveiby [11] holds the view that information is meaningless, and knowledge is interpreted information. Wiig [12] regards information as a combination of facts and data organised to describe situations, while knowledge consists of 'truths and beliefs, perspectives and concepts, judgement and expectations, methodologies and know-how'. The common idea is that data is something less than information, and information is something less than knowledge [13]. However, this does not always imply that data is the prerequisite of information, and that information is the prerequisite of knowledge. Tuomi [13] presents a reversed hierarchy of data, information and knowledge, in which data emerges only after information and knowledge are available. 


\section{$3 \quad$ Research Design}

\subsection{Sampling}

The theoretical sampling method suggests that suitable case companies will help develop reliable theories $[14,15]$, which requires the researcher to select cases based on the theoretical categories of interest in the study.

By considering the aims and focuses of our study, the potential cases should include multi-location companies from one country. The case companies should also have established knowledge management systems. The following criteria are proposed and used to select case companies.

Criterion 1: Case companies need to be multi-location companies that conduct engineering design.

Criterion 2: Case companies need to be companies from the same developing country.

Criterion 3: Case companies need to have established information management facilities and systems.

Meanwhile, the cases should be selected from companies in the same industry. For the purpose of comparison, it is more favourable to have paired cases. This leads to:

Criterion 4: Case companies need to be companies from the same industries, and if possible, cases in the same industry should be paired.

Furthermore, since the researcher's background is in mechanical engineering, cases are selected from companies who design mechanical products so that the researcher can better understand the design activities in these companies. It is also helpful to focus on a specific type of product to cross-compare cases. Therefore, we also specify:

Criterion 5: Case companies need to design mechanical products that the researcher has knowledge of.

Finally, it is important to have easy access to study case companies. The researcher approached companies in the following ways: 1) persuading companies to participate in the study to help understand their information management; and 2) using personal contacts and social network sites such as LinkedIn. Four companies fulfilling the above selection criteria were recruited. The four companies can be regarded as two pairs of cases in two industries in China: machine tools (Company A and Company B) and oil equipment (Company $\mathrm{C}$ and Company $\mathrm{D})$.

\subsection{Data Collection}

Data was collected in 2018, with two visits to each case company. Semi-structured interviews and observations of engineers at work were conducted. The interview process was planned according to Miles and Huberman [16] and Yin [17]. Each participant was interviewed individually on-site. The interviews were recorded with audio devices. Each interview lasted for about one hour. Taped interviews were transcribed immediately after the interview, with notes taken by the researcher. Interviews were followed by observations of engineers at work. Each participant was observed for 32 hours (4 working days). Fours participants were observed in each case company. During the observations, information sheets were used to record participants' 
information queries and the information sources addressed. By the end of the observation study, 512 hours of participants' work were observed and 685 information sheets were filled. A second round of interviews was conducted after the observation study for discussion and feedback to explore further and ensure the accuracy of understanding in the first-round interview.

\subsection{Data Analysis}

Analysis of qualitative data is usually an iterative process to allow intensive interaction between the data and the developing theory [18]. Considering the exploratory nature of this study, the inductive approach was deemed to be the most suitable data analysis approach.

An inductive grounded approach $[16,19,20]$ was adopted for the analysis of the data collected, including transcriptions, fieldwork notes and information sheets.

The coding process resulted in the emergence of four theoretical codes, which were integrated to develop a typology of KMEs for understanding information management in the case companies' engineering design activities. Following configuration theory [21] and organisation theory [22, 23], the typology is developed based on the theoretical codes identified rather than classification of the case companies.

\section{A Typology of KMEs}

Cross-case analysis reveals different strategic orientations of KME. Three types of orientation are identified in the cases, namely project based, document-possessor based and integration orientation. These are a set of ideal types that are developed conceptually. Being ideal types, a real firm can get close to several types rather than realising one single type.

\subsection{Project Based KMEs}

Typical cases with project-oriented KME include Company A and Company D. In project based KMEs, knowledge is stored based on which project it belongs to. The advantage of this approach is that project files can be easily found in the database when a user knows which project the knowlegde belongs to. In Company A's database, participants search through documents directly within a tree-shaped hierarchy that allows users to navigate the content directly [24]. From a strategic perspective, a project based KME is straightforward and easy to manage. With unrestricted access to sufficient information sources, engineers can explore with the help of retrieval systems. However, engineers may get lost easily in the massive irrelevant results, if retrievals systems cannot get required knowledge for engineers.

\subsection{Document-Possessor Based KMEs}

Company B is a typical case with document-possessor oriented KME. In documentpossessor oriented KMEs, information is stored based on the author or the owner of the 
documents. Knowledge is accessible for participants when they know whom filed it. The advantage of this KME is that the company has control of potential confidentiality issues. From a strategic perspective, an engineer who is familiar with the company database is able to identify the required knowledge. Companies have good control of information security, while engineers have to direct access to knowledge.

\subsection{Integration in Workflow}

Company $\mathrm{C}$ is a typical example of a company with integration-oriented KME, which is more complicated than the two orientations above. Integration-oriented KME focuses on capturing, storing and reusing design-relevant solutions [25, 26, 27], with internal integrated procedures to collaboratively assist knowledge management. Such integrative collaboration operates a series of activities to collect, document and share knowledge for design or product development, distributing the product performance and service records to engineers in different departments. The integration-orientated nature of KME makes use of human sources and knowledge management systems, which results in emphasising engineers' needs for design.

\section{Conclusion}

The study reported focuses on the KME of multi-location companies. It has been shown that there is an increasing tendency for design development to be completed by departments from different countries in a multi-national company by collaborating with external partners or contracted design consultancy firms. The typology of KMEs enable companies understand their knowledge management for design activities. By providing reliable and usable support for engineers, companies' product design can be improved, which results in good quality products delivered on time at low cost. In return, the company will remain competitive in the global markets.

\section{References}

1. Ahmed, S.: Encouraging Reuse of Design Knowledge: A Method to Index Knowledge. Design Studies 26(6), 565-592 (2005).

2. Ettlie, J. E., Kubarek, M.: Design Reuse in Manufacturing and Services. Journal of Product Innovation Management 25(5), 457-472 (2008).

3. Wang, H., Johnson, A. L., Bracewell, R. H.: The retrieval of structured design rationale for the re-use of design knowledge with an integrated representation. Advanced Engineering Informatics 26(2), 251-266 (2012).

4. Eckert, C., Maier, A., McMahon, C.: Communication in design. In J. Clarkson and C. Eckert, ed., Design Process Improvement: A Review of Current Practice. Spinger-Verlag, London (2005).

5. Jagtap, S. N.: Capture and structure of in-service information for engineering designers. PhD Dissertation, University of Cambridge (2008). 
6. Heisig, P., Caldwell, N. H. M., Grebici, K., Clarkson, P. J.: Exploring knowledge and information needs in engineering from the past and for the future - results from a survey. Design Studies 31(5), 499-532 (2010).

7. Reed, N., Scanlan, J., Wills, G., Halliday, S. T.: Knowledge Use in An Advanced Manufacturing Environment. Design Studies 32(3), 292-312 (2011).

8. Ackoff, R. L.: Ackoff's Best: his classic writings on management. John Wiley and Sons, New York (1999).

9. Spek, R., Spijkervet, A.: Knowledge Management: Dealing Intelligently with Knowledge. Utrecht: Kenniscentrum CIBIT (1997).

10. Davenport, T. H.: Ten principles of knowledge management and four case studies. Knowledge and process management 4(3), 187-208 (1997).

11. Sveiby, K. E.: The New Organizational Wealth: Managing and Measuring KnowledgeBased Assets. Berrett-Koehler, San Francisco (1997).

12. Wiig, K. M.: Thinking About Thinking - How People and Organizations Create, Represent, and Use Knowledge. Schema Press, Arlington TX (1993).

13. Tuomi, I.: Data is more than knowledge: implications of the reversed knowledge hierarchy for knowledge management and organizational memory. Journal of Management Information Systems 16(3), 103-117 (1999).

14. Eisenhardt, K. M.: Better stories and better constructs- the case for rigor and comparative logic. Academy of Management Review 16(3), 620-627 (1991).

15. Siggelkow, N.: Persuasion with case studies. Academy of Management Journal 50(1), 2024 (2007).

16. Miles, M. B., Huberman, A. M.: Qualitative data analysis: An expanded sourcebook. 2nd ed. Sage, Thousand Oaks (1994).

17. Yin, R. K.: Case study research: Design and methods. 2nd ed. Sage, Thousand Oaks (1994).

18. Dey, I.: Qualitative data analysis: A user-friendly guide for social scientists. Routledge, London (2003).

19. Glaser, B. G.. Strauss, A. L.: The discovery of grounded theory: Strategies of qualitative research. Routledge, London (2017).

20. O'Reilly, K., Paper, D., Marx, S.: Demystifying grounded theory for business research. Organizational Research Methods 15(2), 247-262 (2012).

21. Meyer, A. D., Tsui, A. S., Hinings, C. R.: Configurational approaches to organizational analysis. Academy of Management Journal 36(6), 1175-1195 (1993).

22. Shi, Y., Gregory, M.: International manufacturing networks- to develop global competitive capabilities. Journal of Operations Management 16(2-3), 195-214 (1998).

23. Zander, U., Kogut, B.: Knowledge and the speed of the transfer and imitation of organizational capabilities - an empirical test. Organization Science 6(1), 76-92 (1995).

24. Vijaykumar, G., Chakrabarti, A.: Taxonomy for understanding knowledge captured in documents by designers. In: Proceedings of 16th International Conference on Engineering Design (ICED07), Ecole Centrale, Paris (2007).

25. Liu, S., McMahon, C., Darlington, M. J., Culley, S. J., Wild, P. J.: An automatic mark-up approach for structured document retrieval in engineering design. The International Journal of Advanced Manufacturing Technology 38(3-4), 418-425 (2008).

26. Bracewell, R., Wallace, K., Moss, M., Knott, D.: Capturing design rationale. ComputerAided Design 41(3), 173-186 (2009).

27. Zhang, X., Hou, X., Chen, X., Zhuang, T.: Ontology-based semantic retrieval for engineering domain knowledge. Neurocomputing 116, 383-391 (2013). 